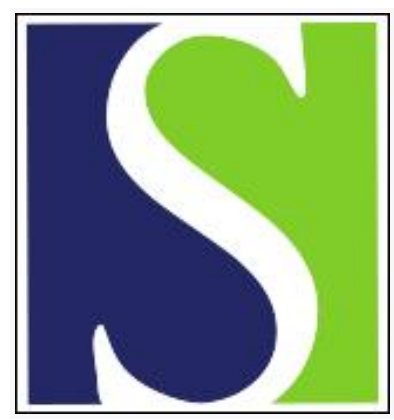

Scand J Work Environ Health 2013;39(3):302-309

https://doi.org/10.5271/sjweh.3330

Published online: 30 Oct 2012, Issue date: 01 May 2013

Risk of cryptorchidism and hypospadias among boys of maternal hairdressers - a Danish population-based cohort study

by Jørgensen $\mathrm{KT}$, Jensen MS, Toft GV, Larsen AD, Bonde JP, Hougaard KS

Maldevelopment of children of women working as hairdressers has been a concern because of exposure to endocrine disrupters. Maternal occupation as hairdresser and risk of cryptorchidism and hypospadias was examined in a cohort of more than 500000 male infants of occupationally active women. Boys of hairdressers were not at increased risk of cryptorchidism or hypospadias compared to other boys.

Affiliation: Department of Occupational and Environmental Medicine, Bispebjerg Hospital, DK-2400 Copenhagen NV, Denmark. kjoe0163@bbh.regionh.dk

Refers to the following texts of the Journal: 1995;21(5):325-334 2000;26(2):137-145 2005;31(3):212-217 2006;32(1):61-66

Key terms: cohort study; cryptorchidism; Denmark; endocrine-disrupting compound; hairdresser; hypospadias; maldevelopment; male reproductive tract; maternal occupation; population-based cohort study

This article in PubMed: www.ncbi.nlm.nih.gov/pubmed/23111987

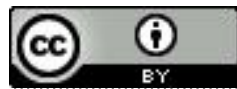




\title{
Risk of cryptorchidism and hypospadias among boys of maternal hairdressers - a Danish population-based cohort study
}

\author{
by Kristian Tore Jørgensen, MSc, PhD, 1, 2 Morten Søndergaard Jensen, MD, PhD, ${ }^{3}$ Gunnar Vase Toft, MSc, \\ PhD, ${ }^{4}$ Ann Dyreborg Larsen, MSc, ${ }^{1,4}$ Jens Peter Bonde, MD, DMSc, ${ }^{2}$ Karin Sørig Hougaard, MSc, PhD ${ }^{1}$
}

\begin{abstract}
Jørgensen KT, Jensen MS, Toft GV, Larsen AD, Bonde JP, Hougaard KS. Risk of cryptorchidism and hypospadias among boys of maternal hairdressers - a Danish population-based cohort study. Scand J Work Environ Health. 2013;39(3):302-309. doi:10.5271/sjweh.3330
\end{abstract}

\begin{abstract}
Objectives Pregnant hairdressers may be exposed to a mixture of chemicals in their working environment. The possible relationship between these chemical agents and male reproductive tract malformations has raised concern that the working environment of hairdressers might have adverse effects on fetal development. This study assessed the risk of cryptorchidism and hypospadias among boys of maternal hairdressers.

Methods National population-based registers were used to determine maternal occupation and identify cases of cryptorchidism and hypospadias. The cohort comprised all children born in Denmark from 1980-2007. Using Cox regression, we estimated hazard ratios (HR) with 95\% confidence intervals ( $95 \% \mathrm{CI}$ ) for hospitalization for cryptorchidism and hypospadias from 1980-2009.

Results Boys of hairdressers were not at increased risk of cryptorchidism (134 cases, HR 0.91; 95\% CI $0.77-1.08$ ) or hypospadias (33 cases, HR 1.27 ; 95\% CI 0.90-1.79) compared to children of mothers in other occupations (14988 and 2556 cases of cryptorchidism and hypospadias, respectively). Additional analyses using children of shop assistants and receptionists as controls and restricted to (i) firstborns, (ii) cryptorchidism cases with corrective surgery, (iii) specific birth years, and (iv) women without social benefit payments in gestational weeks 8-14 produced consistent results of no increased risk.
\end{abstract}

Conclusion Our nationwide cohort study shows that, despite exposure to a complex chemical milieu, hairdressers do not have an increased risk of having boys with cryptorchidism and hypospadias.

Key terms endocrine-disrupting compound; maldevelopment; male reproductive tract; maternal occupation.

The working environment of hairdressers typically involves the use of a vast number of hair products for washing, bleaching, perming, dyeing, and spraying (1). These hair products contain a variety of chemical agents that hairdressers may be exposed to on a continuous daily basis $(2,3)$. Even though concentrations of single chemicals generally are considered to be low in hairdresser salons (4), the long-term consequences of exposure to the complex chemical mixture are unknown.

Specific chemical ingredients found in hair products have known or suspected hormone-disrupting properties that might interfere with the fetal development of repro- ductive organs. These compounds include hexane, benzene, toluene and metoxypropanol and endocrine-disruptive chemicals (EDC) (eg, alkylphenolic compounds and phthalates) (4-6). EDC exposures have shown associations with the genital diseases cryptorchidism (incomplete testicular descent) and hypospadias (displacement of the urethral opening along the ventral shaft of the penis) (7, 8). Cryptorchidism is a fairly common condition among boys with a prevalence at three months of age estimated to be $1.9 \%$ in Denmark, $1.0 \%$ in the USA, and $2.4 \%$ in the UK (9-12). In contrast, hypospadias only occurs among 2-4 boys per 1000 male births in Europe $(13,14)$.

\footnotetext{
1 The National Research Centre for the Working Environment, Copenhagen, Denmark.

2 Department of Occupational and Environmental Medicine, Bispebjerg Hospital, Copenhagen University Hospital, Copenhagen, Denmark.

3 Perinatal Epidemiology Research Unit, Department of Pediatrics, Aarhus University Hospital, Aarhus, Denmark.

4 Department of Occupational Medicine, Aarhus University Hospital, Aarhus, Denmark.
} 
A number of epidemiological studies have addressed whether hairdressers are at increased risk of having children with birth defects compared to women in other professions. Some studies report that female hairdressers have an increased risk of having children with major malformations such as hypospadias (15-17) while others find no support for an increased risk (18-20). Thus, studies have been conflicting, and - so far - no health problems related to reproduction and fetal development have been identified among hairdressers (21). Nevertheless, health concerns persist especially considering pregnant hairdressers.

In this study, we used Danish nationwide registers to collect information about occupational activities and birth defects to assess the possible association between maternal occupation in hairdressing during pregnancy and risk of cryptorchidism and hypospadias among male infants.

\section{Methods}

\section{Data sources}

Information on childbirths, hospital contacts, and employment status was obtained from the following national registers: the Danish Civil Registration System, the Danish National Patient Registry, the Fertility Database, and the Employment Classification Module from Statistics Denmark. The Danish Civil Registration System is a continuously updated demographic database that covers the entire Danish population (22). It was established on 1 April 1968, after which time all Danish inhabitants have been assigned a unique 10-digit identification number. This register was used to identify children born between 1980-2007. Children and parents were linked through the Fertility Database (23). The Danish National Patient Registry includes information about inpatient hospital contacts in Danish hospitals from 1 January 1977 onwards and outpatient hospital contacts from 1 January 1995 onwards (24) and was used to identify boys diagnosed with cryptorchidism and hypospadias. Since 1976, every person in Denmark $\geq 15$ years old and paying tax has been classified annually according to economic and employment status in the Employment Classification Module, Statistics Denmark (25). This module was used to extract information on the mother's work during the year of the birth of her children.

\section{Cohort}

The cohort included all male offspring born in Denmark from 1 January 1980 to 31 December 2007 and their mothers. We restricted our analyses to male infants of singleton pregnancies whose mothers had an active employment status in the birth year. An active employ- ment status indicated that the most important source of income for a person in a given year came from an employment in the public or private sector.

\section{Exposure}

Exposed boys had a mother who was employed as a hairdresser in the birth year while unexposed boys had mothers in other occupations, or specifically mothers working as shop assistants or receptionists (including information clerks). Thus, the three reference groups were (i) all boys with mothers in other occupations than hairdressing, and boys with mothers working as (ii) shop assistants or (iii) receptionists. Shop assistants and receptionists were selected as specific comparison groups due to similarities in educational and socioeconomic backgrounds (shop assistants) and self-exposure to cosmetics (receptionists). It was not possible to identify receptionists as a specific occupational group before 1991, and we thus only included receptionists as a comparison group for the period 1991-2007.

To identify maternal occupation we used occupational and industrial classification codes from the Employment Classification Module, Statistics Denmark. Hairdressers, shop assistants and receptionists were identified as described in table 1 . Women categorized in other occupations (including shop assistants and receptionists) had an identifiable occupational and industrial classification code (excluding codes for hairdressers) for the relevant year. Thus, women who were unemployed, retired, or still studying were not included in the group of other occupations.

\section{Outcome}

Male singleton offspring were followed for the occurrence of cryptorchidism and hypospadias recorded as diagnoses in the Danish National Patient Registry. The study included primary diagnoses of cryptorchidism with International Classification of Diseases (ICD) version 8 codes 75210, 75211, 75219 and ICD-10 codes Q53, Q531, Q532, and Q539 and of hypospadias ICD-8 codes 75220, 75221, 75222, 75228, 75229 and ICD-10 codes Q540, Q541, Q542, Q548, and Q549.

\section{Statistical analysis}

Male infants were followed for their first primary hospital contact for cryptorchidism and hypospadias in the time period 1 January 1980 to 31 December 2009. Follow-up began at time of birth (during the period 1980-2007) and continued until a diagnosis of cryptorchidism or hypospadias (analyzed separately), loss to follow-up (emigration, disappearance), death, or end of follow-up (31 December 2009), whichever came first. 
We estimated hazard ratios (HR) and 95\% confidence intervals $(95 \% \mathrm{CI})$ using Cox regression to compare the occurrence of cryptorchidism and hypospadias among male infants of mothers working as hairdressers with children of mothers in other occupations. All analyses were adjusted for birth year (1980-1989, 1990-1999, 2000-2007), maternal age $(<20,20-24,25-29,30-34$, $\geq 35$ years) and parity status $(0,1-2, \geq 3$ children $)$, and paternal age $(<20,20-24,25-29,30-34, \geq 35$ years $)$.

\section{Supplementary analysis}

Supplementary analyses were performed to test the robustness of the main findings. First, we restricted the analysis to firstborns. Second, we restricted our cohort to include only women who did not receive any economical social benefits (ie, women who were employed and not on sick leave) during gestational weeks 8-14 for the birth years 1991-2007. We identified these women through the DREAM database (26), which includes information on all public transfer payments for Danish inhabitants on a weekly basis since 1991. Third, we used a stricter cryptorchidism case definition that only included boys who had both a diagnosis of cryptorchidism and orchiopexy (corrective surgery to move undescended testicles into the scrotum). The boys with orchiopexy were recorded with a KKFH00, KKFH01, or KKFH10 code following the Nordic Classification of Surgical Procedures. Finally, to see if possible associations between maternal occupation and cryptorchidism differed according to birth years (too few cases of hypospadias for this analysis), we compared the associations between maternal occupation and cryptorchidism in specific birth year periods (1980-1989, 1990-1999, 2000-2007).

\section{Results}

Overall, 924928 women gave birth to 1748881 children in Denmark from 1 January 1980 to 31 December 2007. After excluding 64382 children from multiple births (including children of pregnancies with unknown number status) and female infants, the cohort comprised 864747 boys born to 631904 women. Of these, 587904 $(68 \%)$ were born while their mothers were registered with an active employment status (in total 462523 women). Furthermore, 5882 male infants were born to 4839 maternal hairdressers, 31515 male infants to 27483 shop assistants and 2011 male infants to 1840 receptionists. The distribution of male infants according to maternal occupation at birth year and number of previous childbirths, year of birth, and maternal and paternal age at birth is shown in table 2 .

\section{Cryptorchidism}

Among the 587904 boys in the cohort, 14988 (2.5\%) were diagnosed with cryptorchidism during follow-up. Of these, 134 boys had a mother who was employed as a hairdresser during the birth year. This corresponded to an overall HR for cryptorchidism among boys of maternal hairdressers of 0.91 (95\% CI $0.77-1.08)$ compared to boys of mothers in all other occupations. Similar overall associations with cryptorchidism were found when comparing maternal hairdressers with maternal shop assistants (HR 0.86; 95\% CI 0.72-1.03) and receptionists (HR 0.89; 95\% CI 0.60-1.33) (table 3).

In the supplementary analyses (tables 4 and 5), we observed HR for cryptorchidism among boys of hairdressers similar to those of the main analysis when we restricted our analyses to: (i) first liveborns (in total 270912 male infants); (ii) women who did not receive any social benefit payments during gestational weeks

Table 1. Occupational and industrial codes used to identify maternal occupation as hairdresser, shop assistant and receptionist during birth years from 1980-2007. [BRANCHE=Danish industrial codes (1977-1993); DISCO-88=Danish version of International Standard Classification of Occupations (1991-2007); NACE=Statistical Classification of Economic Activities in the European Community (19922007) available from the Employment Classification Module, Statistics Denmark; NyStGr=Danish version of International Standard Classification of Occupations (1980-1995)]

\begin{tabular}{|c|c|c|c|c|c|c|c|}
\hline \multirow[t]{3}{*}{ Birth years } & \multicolumn{4}{|c|}{ Hairdressers $^{\text {a }}$} & \multirow{2}{*}{\multicolumn{2}{|c|}{$\begin{array}{c}\text { Shop assistants } \\
\text { Occupational codes }\end{array}$}} & \multirow{3}{*}{$\begin{array}{c}\text { Receptionists } \\
\text { Occupational code } \\
\text { DISCO-88 }\end{array}$} \\
\hline & \multicolumn{2}{|c|}{ Occupational codes } & \multicolumn{2}{|c|}{ Industrial codes } & & & \\
\hline & NyStGr & DISC0-88 & BRANCHE & NACE & NyStGr & DISC0-88 & \\
\hline 1980-1990 & 1363,4559 & & $95911-95913$ & . & 4441 & 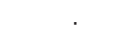 & \\
\hline 1991-1992 & .. & 5141 & $95911-95913$ & . & . & 5220 & $4222^{b}$ \\
\hline 1993-2007 & .. & 5141 & .. & 930210 & . & 5220 & $4222^{b}$ \\
\hline
\end{tabular}

a Women identified as hairdressers had both an occupational and an industrial code related to the hairdressing occupation.

b The DISC0-88 code 4222 includes receptionists and information clerks (hotel assistants, hall porters, clinic assistants, clinic secretaries and information assistants). 
Table 2. Distibution of male offspring according to maternal occupation and number of previous childbirths, year of birth, and maternal and paternal age at birth

\begin{tabular}{|c|c|c|c|c|c|c|c|c|}
\hline & \multicolumn{8}{|c|}{ Maternal occupation } \\
\hline & \multicolumn{2}{|c|}{ Hairdressers } & \multicolumn{2}{|c|}{ Other occupation } & \multicolumn{2}{|c|}{ Shop assistants } & \multicolumn{2}{|c|}{ Receptionists } \\
\hline & $\begin{array}{c}\text { Number of male } \\
\text { offspring }\end{array}$ & $\%$ & $\begin{array}{c}\text { Number of male } \\
\text { offspring }\end{array}$ & $\%$ & $\begin{array}{l}\text { Number of male } \\
\text { offspring }\end{array}$ & $\%$ & $\begin{array}{c}\text { Number of male } \\
\text { offspring }\end{array}$ & $\%$ \\
\hline \multicolumn{9}{|c|}{ Previous childbirths } \\
\hline 0 & 3161 & 53.7 & 267751 & 46.0 & 17702 & 56.2 & 868 & 43.2 \\
\hline $1-2$ & 2643 & 44.9 & 299483 & 51.5 & 13341 & 42.3 & 1093 & 54.4 \\
\hline$\geq 3$ & 71 & 1.2 & 14424 & 2.5 & 452 & 1.4 & 47 & 2.3 \\
\hline Missing & 7 & 0.1 & 364 & 0.1 & 20 & 0.1 & 3 & 0.2 \\
\hline \multicolumn{9}{|l|}{ Year of birth } \\
\hline 1990-1999 & 2003 & 34.1 & 209068 & 35.9 & 11749 & 37.3 & 1205 & 59.9 \\
\hline 2000-2007 & 1890 & 32.1 & 164249 & 28.2 & 7315 & 23.2 & 806 & 40.1 \\
\hline Missing & 0 & 0 & 0 & 0 & 0 & 0 & 0 & 0 \\
\hline \multicolumn{9}{|c|}{ Maternal age at birth } \\
\hline $\begin{array}{l}<20 \text { years } \\
20-24\end{array}$ & $\begin{array}{r}12 \\
1200\end{array}$ & $\begin{array}{r}0.2 \\
20.4\end{array}$ & $\begin{array}{r}3220 \\
76359\end{array}$ & $\begin{array}{r}0.6 \\
13.1\end{array}$ & $\begin{array}{r}419 \\
8654\end{array}$ & $\begin{array}{r}1.3 \\
27.5\end{array}$ & $\begin{array}{r}2 \\
105\end{array}$ & $\begin{array}{l}0.1 \\
52\end{array}$ \\
\hline $25-29$ & 2593 & 44.1 & 218230 & 37.5 & 13605 & 43.2 & 705 & 35.1 \\
\hline $\begin{array}{l}30-34 \\
>35\end{array}$ & $\begin{array}{r}1542 \\
535\end{array}$ & $\begin{array}{r}26.2 \\
9.1\end{array}$ & $\begin{array}{r}198537 \\
85676\end{array}$ & $\begin{array}{l}34.1 \\
14.7\end{array}$ & $\begin{array}{l}6808 \\
2029\end{array}$ & $\begin{array}{r}21.6 \\
6.4\end{array}$ & $\begin{array}{l}869 \\
330\end{array}$ & $\begin{array}{l}43.2 \\
16.4\end{array}$ \\
\hline Missing & 0 & 0 & 0 & 0 & 0 & 0 & 0 & 0 \\
\hline \multicolumn{9}{|c|}{ Paternal age at birth } \\
\hline$<20$ years & 10 & 0.2 & 727 & 0.1 & 91 & 0.3 & 0 & 0 \\
\hline $20-24$ & 517 & 8.8 & 34172 & 5.9 & 4042 & 12.8 & 45 & 2.2 \\
\hline $25-29$ & 2201 & 37.4 & 160259 & 27.5 & 12278 & 39.0 & 474 & 23.6 \\
\hline 30-34 & 2032 & 34.6 & 213916 & 36.8 & 9727 & 30.9 & 841 & 41.8 \\
\hline$\geq 35$ & 1075 & 18.3 & 167379 & 28.8 & 5023 & 15.9 & 618 & 30.7 \\
\hline Missing & 47 & 0.8 & 5569 & 1.0 & 354 & 1.1 & 33 & 1.6 \\
\hline
\end{tabular}

8-14; (iii) cases of cryptorchidism to boys who were also treated with orchiopexy in total comprising 9722 children; and (iv) stratifying by birth year (1980-1989, 1990-1999 and 2000-2007). The latter analysis specifically showed that HR were consistent across birth years and that, at none of the studied birth year periods, boys of maternal hairdressers were at significantly increased or reduced risk for cryptorchidism (table 5).

\section{Hypospadias}

Altogether 2556 boys $(0.4 \%)$ were diagnosed with hypospadias in the study period, 33 of whom had a mother employed as a hairdresser within the birth year. Compared to the risk among boys of mothers in other occupations, this corresponds to a HR of 1.27 (95\% CI 0.90-1.79) for boys of hairdressers. The HR for hypospadias among boys of hairdressers were $1.16(95 \%$ CI 0.79-1.69) and 1.23 (95\% CI 0.59-2.54) compared to boys of maternal shop assistants and receptionists, respectively (table 3 ).

Restricting the cohort to first liveborn children, the analysis provided similar results, ie, the risk of hypospadias was approximately the same regardless of maternal occupation (table 4). In the analysis restricted to the subset of women who did not receive social benefit payments during gestational weeks $8-14$, the results were consistent with those of the main analysis (table 4).

\section{Discussion}

We compared the risk of cryptorchidism and hypospadias among boys of mothers working as hairdressers with boys of mothers in other occupations using one of the largest cohorts to have assessed the risk of male reproductive tract malformations in offspring of hairdressers. The salient observation was that the risk of cryptorchidism and hypospadias did not differ among boys born to maternal hairdressers compared to other boys.

Both cryptorchidism and hypospadias are malformations that can be treated with a good prognosis. However, men with a history of undescended testes may have reduced spermatogenic function and possibly reduced fertility in adulthood, especially if the condition is left untreated for a prolonged period of time $(27,28)$. The development of male reproductive organs depends on androgens and a balanced androgen-estrogen ratio. Therefore, it has been suggested that exposure to high levels of chemicals that interfere with the production or action of sex hormones might disturb the male reproduc- 
Table 3. Hazard ratios (HR) of cryptorchidism and hypospadias among boys according to maternal occupation of 462523 women with 587904 sons born 1980-2007. [95\% Cl=95\% confidence interval.]

\begin{tabular}{|c|c|c|c|c|c|c|c|c|}
\hline & \multirow{2}{*}{$\begin{array}{l}\text { Number of } \\
\text { women }\end{array}$} & \multirow{2}{*}{$\begin{array}{c}\text { Number of male } \\
\text { offspring }^{b}\end{array}$} & \multicolumn{3}{|c|}{ Cryptorchidism } & \multicolumn{3}{|c|}{ Hypospadias } \\
\hline & & & Number of events & $\mathrm{HR}$ & $95 \% \mathrm{Cl}$ & Number of events & $\mathrm{HR}$ & $95 \% \mathrm{Cl}$ \\
\hline Hairdressers & 4839 & 5882 & 134 & 0.91 & $0.77-1.08$ & 33 & 1.27 & $0.90-1.79$ \\
\hline Other occupations & 457684 & 582022 & 14854 & 1.00 & Reference & 2523 & 1.00 & Reference \\
\hline Hairdressers & 4839 & 5882 & 134 & 0.86 & $0.72-1.03$ & 33 & 1.16 & $0.79-1.69$ \\
\hline Shop assistants & 27483 & 31515 & 866 & 1.00 & Reference & 145 & 1.00 & Reference \\
\hline Hairdressers & 3169 & 3734 & 74 & 0.89 & $0.60-1.33$ & 26 & 1.23 & $0.59-2.54$ \\
\hline Receptionists & 1840 & 2011 & 40 & 1.00 & Reference & 11 & 1.00 & Reference \\
\hline
\end{tabular}

${ }^{a}$ Adjusted for maternal and paternal age, number of previous childbirths, and birth year.

${ }^{\mathrm{b}}$ Male offspring in singleton pregnancies.

Table 4. Hazard ratios (HR) of cryptorchidism and hypospadias among first liveborn boys, boys of women not receiving social benefit payments in gestational weeks 8-14, and boys surgically treated for cryptorchidism (orchiopexy) according to maternal occupation. [95\% Cl=95\% confidence interval.]

\begin{tabular}{|c|c|c|c|c|c|c|c|c|c|c|c|c|c|c|c|}
\hline & \multicolumn{9}{|c|}{ Cryptorchidism } & \multicolumn{6}{|c|}{ Hypospadias } \\
\hline & \multicolumn{3}{|c|}{$\begin{array}{l}\text { First liveborn } \\
\text { child }\end{array}$} & \multicolumn{3}{|c|}{$\begin{array}{c}\text { Women receiving no social } \\
\text { benefit payments in } \\
\text { gestational weeks 8-14 }\end{array}$} & \multicolumn{3}{|c|}{$\begin{array}{c}\text { Boys with corrective } \\
\text { surgery }\end{array}$} & \multicolumn{3}{|c|}{$\begin{array}{l}\text { First liveborn } \\
\text { child }\end{array}$} & \multicolumn{3}{|c|}{$\begin{array}{l}\text { Women receiving no } \\
\text { social benefit payments in } \\
\text { gestational weeks 8-14 }\end{array}$} \\
\hline & $\begin{array}{l}\text { Number } \\
\text { of events }\end{array}$ & $\mathrm{HR}$ & $95 \% \mathrm{Cl}$ & $\begin{array}{l}\text { Number } \\
\text { of events }\end{array}$ & $\mathrm{HR}$ & $95 \% \mathrm{Cl}$ & $\begin{array}{l}\text { Number } \\
\text { of events }\end{array}$ & $\mathrm{HR}$ & $95 \% \mathrm{Cl}$ & $\begin{array}{l}\text { Number } \\
\text { of events }\end{array}$ & $\mathrm{HR}$ & $95 \% \mathrm{Cl}$ & $\begin{array}{l}\text { Number } \\
\text { of events }\end{array}$ & $\mathrm{HR}$ & $95 \% \mathrm{Cl}$ \\
\hline Hairdressers & 78 & 0.94 & $0.75-1.17$ & 45 & 0.88 & $0.66-1.18$ & 85 & 0.89 & $0.72-1.11$ & 18 & 1.20 & $0.75-1.91$ & 16 & 1.30 & $0.80-2.13$ \\
\hline $\begin{array}{l}\text { Other } \\
\text { occupations }\end{array}$ & 7251 & 1.00 & Reference & 5260 & 1.00 & Reference & 9637 & 1.00 & Reference & 1271 & 1.00 & Reference & 1238 & 1.00 & Reference \\
\hline Hairdressers & 78 & 0.89 & $0.70-1.13$ & 45 & 0.79 & $0.58-1.08$ & 85 & 0.84 & $0.67-1.06$ & 18 & 1.18 & $0.71-1.97$ & 16 & 1.18 & $0.68-2.05$ \\
\hline $\begin{array}{l}\text { Shop } \\
\text { assistants }\end{array}$ & 505 & 1.00 & Reference & 270 & 1.00 & Reference & 574 & 1.00 & Reference & 83 & 1.00 & Reference & 63 & 1.00 & Reference \\
\hline Hairdressers & 35 & 0.78 & $0.43-1.40$ & 45 & 0.85 & $0.52-1.40$ & 40 & 0.77 & $0.45-1.31$ & 13 & 0.66 & $0.27-1.64$ & 16 & 1.06 & $0.44-2.52$ \\
\hline Receptionists & 18 & 1.00 & Reference & 26 & 1.00 & Reference & 24 & 1.00 & Reference & 8 & 1.00 & Reference & 8 & 1.00 & Reference \\
\hline
\end{tabular}

${ }^{a}$ Adjusted for maternal and paternal age, number of previous childbirths and birth year.

Table 5. Hazard ratios (HR) of cryptorchidism among boys according to birth year and maternal occupation of 462523 women with 587904 male offspring born between 1980-2007. [95\% Cl=95\% confidence interval.]

\begin{tabular}{|c|c|c|c|c|c|c|c|c|c|}
\hline & \multicolumn{3}{|c|}{ Year of birth $1980-1989$} & \multicolumn{3}{|c|}{ Year of birth 1990-1999 } & \multicolumn{3}{|c|}{ Year of birth 2000-2007 } \\
\hline & Number of events & $\mathrm{HR}$ & $95 \% \mathrm{Cl}$ & Number of events & $\mathrm{HR}$ & $95 \% \mathrm{Cl}$ & Number of events & $\mathrm{HR}$ & $95 \% \mathrm{Cl}$ \\
\hline Hairdressers & 56 & 0.90 & $0.70-1.18$ & 42 & 0.87 & $0.64-1.18$ & 36 & 0.96 & $0.69-1.33$ \\
\hline Other occupations & 6539 & 1.00 & Reference & 5002 & 1.00 & Reference & 3313 & 1.00 & Reference \\
\hline Hairdressers & 56 & 0.86 & $0.65-1.13$ & 42 & 0.80 & $0.58-1.11$ & 36 & 0.97 & $0.67-1.40$ \\
\hline Shop assistants & 410 & 1.00 & Reference & 306 & 1.00 & Reference & 150 & 1.00 & Reference \\
\hline Hairdressers & . & . & .. & 38 & 0.95 & $0.57-1.59$ & 36 & 0.80 & $0.42-1.51$ \\
\hline Receptionists & . & . & .. & 26 & 1.00 & Reference & 14 & 1.00 & Reference \\
\hline
\end{tabular}

${ }^{a}$ Adjusted for maternal and paternal age, number of previous childbirths and birth year.

tive tract development (7). This hypothesis has been supported by a number of previous observations. In a Spanish case-control study, placental levels of xenoestrogenic activity were increased among children with cryptorchidism or hypospadias compared to children without these genital tract malformations (29). Assessments of possible adverse health effects of chemicals have generally been restricted to single chemical compounds and not mixtures. One group of chemicals that has been given particular focus is the EDC with possible effects of maternal occupational exposure mostly assessed through a job exposure matrix where hairdressers constituted one of the largest single occupational groups with a probable exposure to EDC (6). 
These studies have generally included hypospadias as an outcome but not cryptorchidism. Studies from Australia, Italy, and Denmark have shown relative risks of 1.3-2.4 for hypospadias among boys of mothers with a potential exposure to EDC during pregnancy compared to boys of mothers in occupations where EDC exposure is unlikely (30-32). Moreover, an English case-control study found that occupational exposure to hair spray was associated with a relative risk of 2.3 for hypospadias. Although hairdressers as a group displayed a 2.7 -fold increase in risk, this did not reach statistical significance (33). Two Swedish cohort studies have assessed the reproductive outcomes of hairdressers and found a relative risk of 1.3 of major malformations, including hypospadias, in a study from 2002 but found no association in a more recent study from $2005(17,18)$.

The results of the current study do not support the notion that boys of female hairdressers are at increased risk of cryptorchidism and hypospadias. Although we only identified 33 boys with hypospadias among children of hairdressers, our findings are in line with other studies on hairdressers reporting no association with hypospadias $(18,19)$, cryptorchidism (32), or malformations in general (20). Presumably the levels of exposure to chemical agents, for instance with endocrine-disrupting properties, in hairdressing salons are of insufficient magnitude to interfere adversely with the development of the male reproductive tract. The exposure level has plausibly been reduced within the last decades due to a ban of some hazardous chemicals and increased attention to working conditions (eg, in relation to ventilation) $(2,34)$. It might thus be expected that children of hairdressers born in the 1980s or 1990s had a higher exposure and thus possibly a higher relative risk than children born in the 2000s. However, our results do not suggest that boys of hairdressers born in earlier recent decades were at higher risk than other children born in the same years.

Shop assistants and receptionists were chosen as specific comparison groups to minimize the potential confounding effect of socioeconomic-related factors and personal use of cosmetics. Hairdressers and shop assistants were assumed to have the same level of education, income, and other socioeconomic factors, while receptionists were assumed to have a personal use of cosmetics similar to that of hairdressers. We found the risk of cryptorchidism and hypospadias to be similar among sons of hairdressers and the various comparison groups.

We tested the robustness of our findings in supplementary analyses that were restricted to (i) women who had not previously given birth to liveborn children; (ii) occupationally active women who did not receive any social benefit payments in gestational weeks $8-14$, thus increasing the probability that these women were actually working during the gestational period assumed to repre- sent the most important time window for perturbation of development of the male reproductive tract (35); and (iii) cryptorchidism cases with corrective surgery (orchiopexy). Taken together, the consistent and comparable results provided additional support for the finding that the hairdressing occupation is not a high-risk occupation for maldevelopment of the male reproductive tract.

Our study has some potential limitations that need consideration. Congenital cases of transient cryptorchidism may never be clinically recognized and recorded in the Danish National Patient Registry because spontaneous descent is frequent during the first months of life. Furthermore, it has been shown that the register-based cumulative incidence of cryptorchidism and hypospadias in the Danish population increases after the age of $10(32,36)$. Thus, studies relying on registerbased recordings of cryptorchidism may likely, to some degree, underestimate mild and transient cases of cryptorchidism. Furthermore, an unknown proportion of mild hypospadias are never hospitalized. Therefore hypospadias reported in the Danish National Patient Registry presumably to a larger degree include more severe than mild cases. Nevertheless, the observed prevalences of $2.5 \%$ and $0.4 \%$ of cryptorchidism and hypospadias, respectively, in the cohort of sons of employed mothers resemble those reported in other studies (9-14), and high positive predictive values have been found for the diagnosis of cryptorchidism $(80 \%)$ and the registration of orchiopexy (99\%) in the Danish National Patient Registry (37). Finally, the Danish healthcare system is free of charge and accessible to all Danish citizens, and we do not expect underestimation of cryptorchidism and hypospadias to differ between the occupational groups examined in this study. We used the Employment Classification Module provided by Statistics Denmark to determine each individual's affiliation to the Danish labor market. The Employment Classification Module includes information on the most important employment activity in terms of income throughout each year and, although this information has not been validated, the register is generally considered to be of high quality (25). The total number of women employed as hairdressers in Denmark at some time point during the study period is likely considerably higher than the 4839 women identified in this study; for instance, the Danish Hairdressers and Beauticians Union report that they had 5374 members in 2006. However, this discrepancy was expected as we only included that subset of women who conceived during their employment as hairdressers. Also, when identifying women as hairdressers, we required occupational and industrial classification codes that were specifically related to employment as a hairdresser and in a hairdressing salon, respectively. Consequently, the specificity of women categorized as hairdressers in this study is likely high. 


\section{Concluding remarks}

This study found no evidence for an increased risk of malformations of the male reproductive tract among boys of maternal hairdressers. It must, however, be stressed that exposure levels and prevalence within the hairdressing occupation may vary substantially, and thus we cannot exclude the possibility that the occupational environment for some hairdressers might potentially disturb fetal development, including urethral fusion and testicular descent. However, when considering the hairdressing occupation as a whole, our findings show that boys of maternal hairdressers have the same risk of cryptorchidism and hypospadias as boys of mothers in other occupations.

\section{Acknowledgments}

The authors declare no conflicts of interest. This study is supported by grants from the Danish Working Environment Research Foundation (20080016458) to the MINERVA project and the Danish Research Council (10-082745). The authors are grateful to Michael V Christensen for expert management of the DREAM data and to Harald Hannerz for merging data on children, parents, and occupations.

\section{References}

1. Kersemaekers WM, Roeleveld N, Zielhuis GA. Reproductive disorders due to chemical exposure among hairdressers. Scand J Work Environ Health. 1995; 21(5):325-34. http://dx.doi. org/10.5271/sjweh.46.

2. Hollund BE, Moen BE. Chemical exposure in hairdresser salons: effect of local exhaust ventilation. Ann Occup Hyg. 1998;42(4):277-82.

3. van der Wal J.F, Hoogeveen AW, Moons AM, Wouda P. Investigation on the exposure of hairdressers to chemical agents. Environ Int. 1997;23(4):433-9. http://dx.doi. org/10.1016/S0160-4120(97)00031-7.

4. Ronda E, Hollund BE, Moen BE. Airborne exposure to chemical substances in hairdresser salons. Environ Monit Assess. 2009;153(1-4):83-93. http://dx.doi.org/10.1007/ s10661-008-0338-y.

5. Brouwers MM, van TM, Hirst AA, Bretveld RW, Roeleveld N. Occupational exposure to potential endocrine disruptors: further development of a job exposure matrix. Occup Environ Med. 2009;66(9):607-14. http://dx.doi.org/10.1136/ oem.2008.042184.

6. van Tongeren M., Nieuwenhuijsen MJ, Gardiner K, Armstrong B, Vrijheid M, Dolk $\mathrm{H}$ et al. A job-exposure matrix for potential endocrine-disrupting chemicals developed for a study into the association between maternal occupational exposure and hypospadias. Ann Occup Hyg. 2002;46(5):465-77. http:// dx.doi.org/10.1093/annhyg/mef053.

7. Fisher JS. Environmental anti-androgens and male reproductive health: focus on phthalates and testicular dysgenesis syndrome. Reproduction. 2004; 127(3):305-15. http://dx.doi.org/10.1530/rep.1.00025.

8. Main KM, Skakkebaek NE, Virtanen HE, Toppari J. Genital anomalies in boys and the environment. Best Pract Res Clin Endocrinol Metab. 2010;24(2):279-89. http://dx.doi. org/10.1016/j.beem.2009.10.003.

9. Acerini CL, Miles HL, Dunger DB, Ong KK, Hughes IA. The descriptive epidemiology of congenital and acquired cryptorchidism in a UK infant cohort. Arch Dis Child. 2009;94(11):868-72. http://dx.doi.org/10.1136/ adc.2008.150219.

10. Ansell PE, Bull D, Chilvers CED, Coupland CAC, Pike MC. Cryptorchidism: a prospective study of 7500 consecutive male births, 1984-8. John Radcliffe Hospital Cryptorchidism Study Group. Arch Dis Child. 1992;67(7):892-9. http://dx.doi. org/10.1136/adc.67.7.892.

11. Berkowitz GS, Lapinski RH, Dolgin SE, Gazella JG, Bodian CA, Holzman IR. Prevalence and natural history of cryptorchidism. Pediatrics. 1993;92(1):44-9.

12. Boisen KA, Kaleva M, Main KM, Virtanen HE, Haavisto AM, Schmidt IM et al. Difference in prevalence of congenital cryptorchidism in infants between two Nordic countries. Lancet. 2004;363(9417):1264-9. http://dx.doi.org/10.1016/ S0140-6736(04)15998-9.

13. Dolk H, Loane M, Garne E. The prevalence of congenital anomalies in Europe. Adv Exp Med Biol. 2010;686:349-64. http://dx.doi.org/10.1007/978-90-481-9485-8_20.

14. Pierik FH, Burdorf A, Nijman JM, de Muinck Keizer-Schrama SM, Juttmann RE, Weber RF. A high hypospadias rate in The Netherlands. Hum Reprod. 2002;17(4):1112-5. http://dx.doi. org/10.1093/humrep/17.4.1112.

15. Kersemaekers WM, Roeleveld N, Zielhuis GA. Reproductive disorders among hairdressers. Epidemiology. 1997;8(4):396401. http://dx.doi.org/10.1097/00001648-199707000-00008.

16. Lorente C, Cordier S, Bergeret A, De Walle HE, Goujard J, Ayme $\mathrm{S}$ et al. Maternal occupational risk factors for oral clefts. Occupational Exposure and Congenital Malformation Working Group. Scand J Work Environ Health. 2000;26(2):137-45. http://dx.doi.org/10.5271/sjweh.523.

17. Rylander L, Axmon A, Toren K, Albin M. Reproductive outcome among female hairdressers. Occup Environ Med. 2002;59(8):517-22. http://dx.doi.org/10.1136/oem.59.8.517.

18. Rylander L, Kallen B. Reproductive outcomes among hairdressers. Scand J Work Environ Health. 2005;31(3):21217. http://dx.doi.org/10.5271/sjweh.871.

19. Vrijheid M, Armstrong B, Dolk H, van TM, Botting B. Risk of hypospadias in relation to maternal occupational exposure to potential endocrine disrupting chemicals. Occup Environ Med. 2003;60(8):543-50. http://dx.doi.org/10.1136/oem.60.8.543. 
20. Zhu JL, Vestergaard M, Hjollund NH, Olsen J. Pregnancy outcomes among female hairdressers who participated in the Danish National Birth Cohort. Scand J Work Environ Health. 2006;32(1):61-6. http://dx.doi.org/10.5271/sjweh.977.

21. Peters C, Harling M, Dulon M, Schablon A, Torres CJ, Nienhaus A. Fertility disorders and pregnancy complications in hairdressers - a systematic review. J Occup Med Toxicol. 2010;5:24. http://dx.doi.org/10.1186/1745-6673-5-24.

22. Pedersen CB. The Danish Civil Registration System. Scand J Public Health. 2011;39(7 Suppl):22-5. http://dx.doi. org/10.1177/1403494810387965.

23. Blenstrup LT, Knudsen LB. Danish registers on aspects of reproduction. Scand J Public Health. 2011;39(7 Suppl):79-82. http://dx.doi.org/10.1177/1403494811399957.

24. Lynge E, Sandegaard JL, Rebolj M. The Danish National Patient Register. Scand J Public Health. 2011;39(7 Suppl):30-3. http://dx.doi.org/10.1177/1403494811401482.

25. Petersson F, Baadsgaard M, Thygesen LC. Danish registers on personal labor market affiliation. Scand J Public Health. 2011;39(7 Suppl):95-8. http://dx.doi.org/10.1177/1403494811408483.

26. Hjollund NH, Larsen FB, Andersen JH. Register-based followup of social benefits and other transfer payments: accuracy and degree of completeness in a Danish interdepartmental administrative database compared with a population-based survey. Scand J Public Health. 2007;35(5):497-502. http:// dx.doi.org/10.1080/14034940701271882.

27. Ashley RA, Barthold JS, Kolon TF. Cryptorchidism: pathogenesis, diagnosis, treatment and prognosis. Urol Clin North Am. 2010;37(2):183-93. http://dx.doi.org/10.1016/j. ucl.2010.03.002.

28. Virtanen HE, Bjerknes R, Cortes D, Jorgensen N, Rajpert-De ME, Thorsson AV, et al. Cryptorchidism: classification, prevalence and long-term consequences. Acta Paediatr. 2007;96(5):611-6. http://dx.doi.org/10.1111/j.1651-2227.2007.00241.x.

29. Fernandez MF, Olmos B, Granada A, Lopez-Espinosa MJ, Molina-Molina JM, Fernandez JM, et al. Human exposure to endocrine-disrupting chemicals and prenatal risk factors for cryptorchidism and hypospadias: a nested case-control study. Environ Health Perspect. 2007;115 Suppl 1:8-14. http:// dx.doi.org/10.1289/ehp.9351.
30. Nassar N, Abeywardana P, Barker A, Bower C. Parental occupational exposure to potential endocrine disrupting chemicals and risk of hypospadias in infants. Occup Environ Med. 2010;67(9):585-9. http://dx.doi.org/10.1136/ oem.2009.048272.

31. Giordano F, Abballe A, De FE, di DA, Ferro F, Grammatico $\mathrm{P}$, et al. Maternal exposures to endocrine disrupting chemicals and hypospadias in offspring. Birth Defects Res A Clin Mol Teratol. 2010;88(4):241-50.

32. Morales-Suarez-Varela MM, Toft GV, Jensen MS, RamlauHansen C, Kaerlev L, Thulstrup AM, et al. Parental occupational exposure to endocrine disrupting chemicals and male genital malformations: a study in the Danish National Birth Cohort study. Environ Health. 2011;10(1):3. http:// dx.doi.org/10.1186/1476-069X-10-3.

33. Ormond G, Nieuwenhuijsen MJ, Nelson P, Toledano MB, Iszatt $\mathrm{N}$, Geneletti $\mathrm{S}$, et al. Endocrine disruptors in the workplace, hair spray, folate supplementation, and risk of hypospadias: case-control study. Environ Health Perspect. 2009;117(2):303-7.

34. Leino T, Kahkonen E, Saarinen L, Henriks-Eckerman ML, Paakkulainen H. Working conditions and health in hairdressing salons. Appl Occup Environ Hyg. 1999;14(1):26-33. http:// dx.doi.org/10.1080/104732299303386.

35. Welsh M, Saunders PT, Fisken M, Scott HM, Hutchison GR, Smith LB, et al. Identification in rats of a programming window for reproductive tract masculinization, disruption of which leads to hypospadias and cryptorchidism. J Clin Invest. 2008;118(4):1479-90. http://dx.doi.org/10.1172/JCI34241.

36. Jensen MS, Olsen LH, Thulstrup AM, Bonde JP, Olsen J, Henriksen TB. Age at cryptorchidism diagnosis and orchiopexy in Denmark: a population based study of 508,964 boys born from 1995 to 2009. J Urol. 2011;186(4 Suppl):1595-1600. http://dx.doi.org/10.1016/j.juro.2011.03.070.

37. Jensen MS, Snerum TM, Olsen LH, Thulstrup AM, Bonde $\mathrm{JP}$, Olsen J, et al. Accuracy of cryptorchidism diagnoses and corrective surgical treatment registration in the danish national patient registry. J Urol. 2012;188(4):1324-9. http://dx.doi. org/10.1016/j.juro.2012.0s6.045.

Received for publication: 28 July 2012 